\title{
SURFACE DEFORMATION, ABSOLUTE MOVEMENT AND MASS BALANCE OF THE BRUNT ICE SHELF NEAR HALLEY BAY, 1961
}

\author{
By Dennis A. Ardus
}

\begin{abstract}
The surface deformation of the Brunt Ice Shelf in the vicinity of Halley Bay has been determined and these results are used for the calculation of the mass balance of the area. Areas of the ice shelf near Halley Bay which are in a state of equilibrium lose approximately $20-25 \mathrm{~cm} . \mathrm{yr}^{-1}$ of water from their lower surface by bottom melting. This is equivalent to $60-70$ per cent of the net accumulation, the remainder of which is dissipated by spreading. Increased melting from the lower surface and higher rates of spreading cause thinning adjacent to the ice front. The absolute movement of the Brunt Ice Shelf at Halley Bay in 1961 has been calculated as $363 \pm 3 \mathrm{~m} . \mathrm{yr}^{-1}{ }^{-1}$ in a direction $241^{\circ} \pm 10^{\circ}$ east of true north.
\end{abstract}

IN order to obtain a quantitative statement of the mass balance of an ice shelf it is necessary to know the net accumulation of the area, the amount of spreading taking place and the thickness of the ice shelf. If the ice shelf is in a state of equilibrium, then for a given period:

$$
\frac{\text { Net accumulation }}{\text { Equilibrium thickness }}=\text { Increase of area per unit area }
$$

(Swithinbank, 1958, p. 92). If these terms do not equate and a uniform velocity of spreading at all depths is assumed, the discrepancy indicates the amount of bottom melting or freezing which is taking place.

The first of these factors, the net accumulation, has been determined for the Brunt Ice Shelf (Fig. 1) for 1960 and 1961 (Ardus, 1965, p. 26). Measurements of the elevation of the ice shelf between 1956 and 1961 have facilitated the calculation of the thickness of ice during that period (Robin, 1958, p. 113), and surveys of a stake pattern over $27 \mathrm{~km} .{ }^{2}$ in 1960-61 and 1961-62

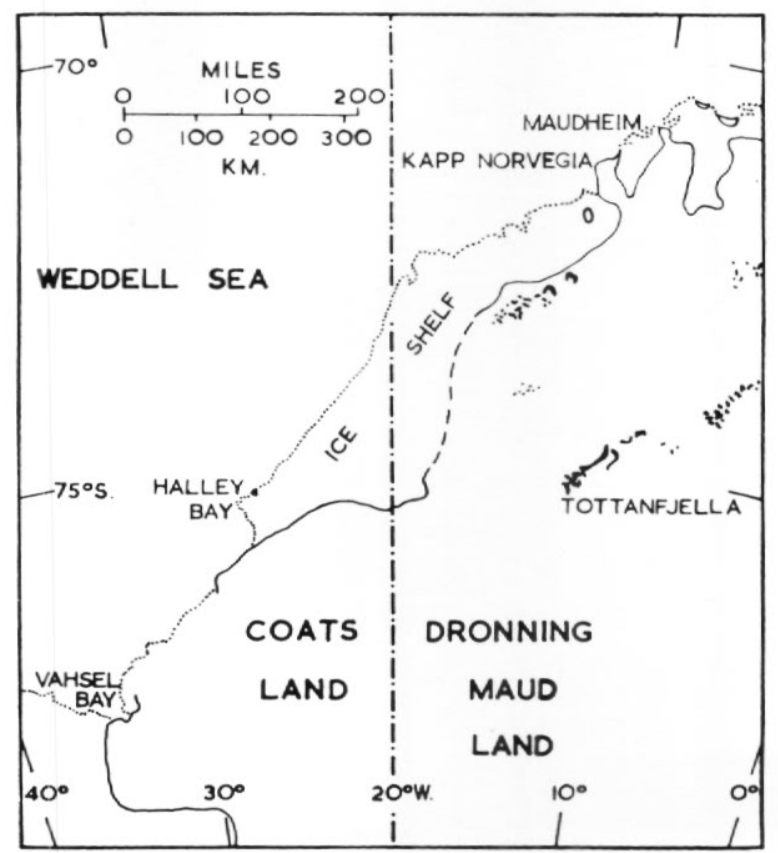

Fig. 1. Sketch map showing the relationship between the Brunt Ice Shelf (near Halley Bay) and the inland ice west of Tottanfjella. 
have been used to determine the surface deformation of the area. In the absence of any fixed points on which to base these surveys, absolute movement measurements were made using grounded icebergs as fixed points.

\section{Elevation of the Ice Shelf}

Repeated levelling from sea-level in Halley Bay to the snow surface around stake C3 (Fig. 2) between 1956 and 1961 has shown the maintenance of a constant elevation at this point, within the error of the survey and the degree of surface roughness, of $28.6 \mathrm{~m}$. above sea-level.

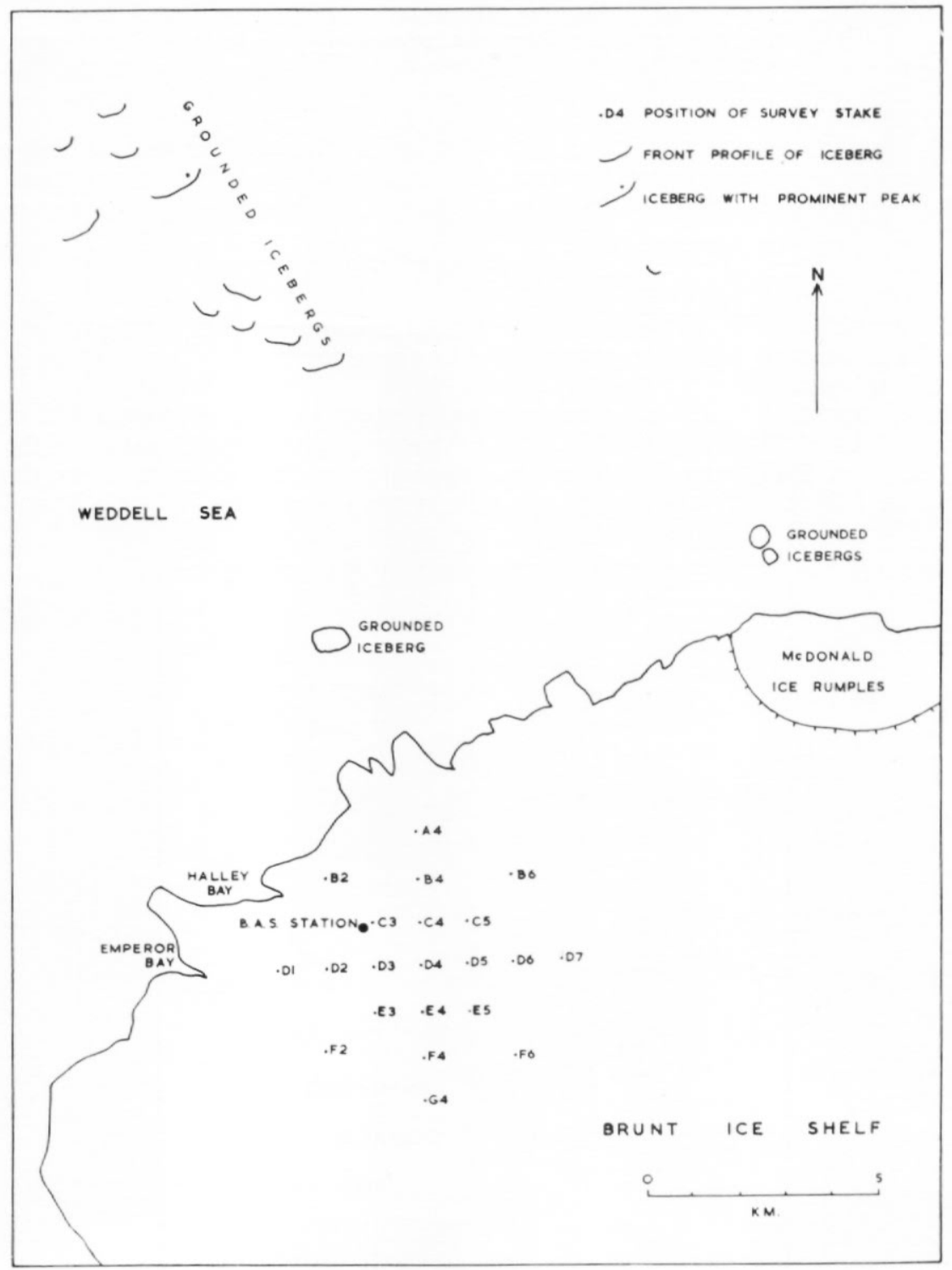

Fig. 2. Map of the Halley Bay area showing the layout of the relative movement stake pattern. The ice front was plane-tabled on 1 January 1962. 
From this elevation the thickness of the ice shelf at this point has been calculated as $137 \mathrm{~m}$. (Robin, 1958, p. 113).

Echo-sounding in 1960 by R.R.S. John Biscoe in Halley Bay, off Emperor Bay and to the south gave depths between 205 and $215 \mathrm{~m}$., while in 1963 an ice thickness of $145 \mathrm{~m}$. was measured at the McDonald Ice Rumples where the ice shelf is aground.

\section{Surface Deformation}

The Brunt Ice Shelf in the neighbourhood of Halley Bay provides good conditions for plane triangulation and trilateration of a stake pattern over a large area. Because of the relatively flat terrain, topographical problems are negligible but, unfortunately, the absence of any rock outcrop on which to base the measurements creates immense difficulties in the computation of the surveys.

In 1960 a pattern of 21 stakes was established over $27 \mathrm{~km} .{ }^{2}$ of ice shelf in the Halley Bay area (Fig. 2). It was planned to fix the relative position of each of these stakes by trilateration and plane triangulation, and then by a re-survey after a known period to determine the amount of relative movement.

\section{The surveys}

The stakes used for the survey were all of light aluminium alloy tubing, in sections $2 \mathrm{~m}$. long and $2.5 \mathrm{~cm}$. in diameter, jointed by a short length of Tufnol tubing fixed to the lower section with Araldite. This enabled the upper section of a stake to be removed in order to position the theodolite directly over the stake for making observations. Each stake carried a red flag for ease of location during the surveys. Originally, several ramin wood stakes formed part of the pattern but these were replaced by aluminium alloy stakes. None of these stakes were bent, despite prolonged periods of high winds, and the only damage which occurred was one broken Tufnol joint. Fortunately, the lower section of this stake remained in place and the upper part was easily replaced. The stakes were maintained as near vertical as possible, but slight inclination of some stakes occurred rarely. However, the horizontal displacement of the recorded position of such a stake is unlikely to have exceeded $5 \mathrm{~cm}$. The lowest visible part of a stake was used in angle observations.

A Tavistock transit theodolite, which reads direct to $1 \mathrm{sec}$. of arc, was used for all angular measurements throughout the surveys. This was set up directly over the position of a stake after the temporary removal of the upper section of the stake. In order to increase the stability of the theodolite tripod a portable triangular Dexion frame, buried to a depth of $20-30 \mathrm{~cm}$., was used as a stand. The erection of the theodolite and tripod on this frame is shown in Figs. 3 and 4. With this arrangement it was possible to complete a set of observations without re-levelling the theodolite. Two pairs of face left and face right observations were regarded as a minimum to establish any direction but, because of the relative flatness of the topography, only the horizontal circle was read.

To determine the distance between stakes and to provide base lines on which to base the theodolite triangulation, trilateration was carried out using D.O.S. $300 \mathrm{ft} . \times \frac{1}{8}$ in. steel tapes, Nos. A128 and A7. Both tapes had to be used for the surveys, because A128 was unfortunately broken. However, their lengths relative to one another were established and these have since been corrected to the National Physical Laboratory certified length of tape A7. The measurements were converted to metres during computation.

The smoothness of the snow surface allowed a high accuracy of measurement to be maintained with the tape resting on the snow surface and held at the required tension with a spring balance. The temperature of the tape was assumed to be the same as that of a thermometer resting on the snow surface, except in instances where strong insolation raised the temperature of the tape to freezing point. This was readily apparent because in these conditions water droplets appeared on the tape. The necessary temperature corrections were applied to each measurement, using the equation for linear thermal expansion given by the National Physical Laboratory for each tape. Distances were measured twice on the same day and the mean of the results adopted. The accuracy attained was greater than 1 part in 30,000 . 


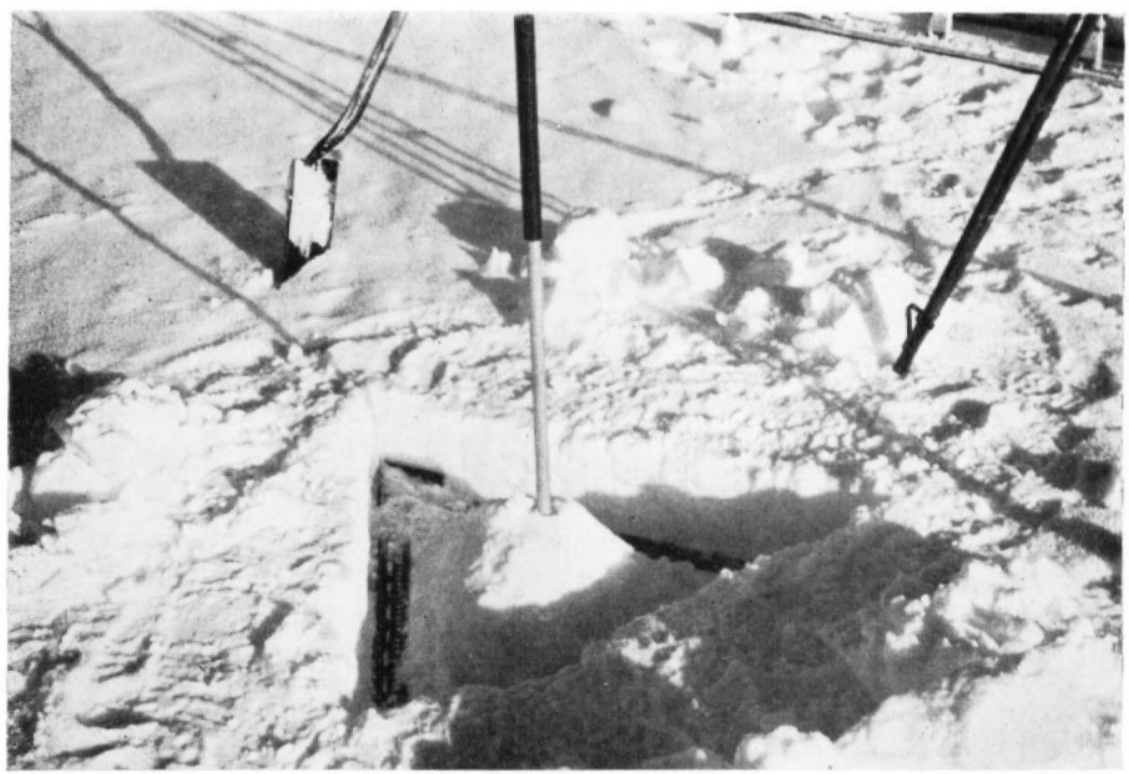

Fig. 3. The emplacement of the portable Dexion frame which was used as a base for the theodolite tripod.

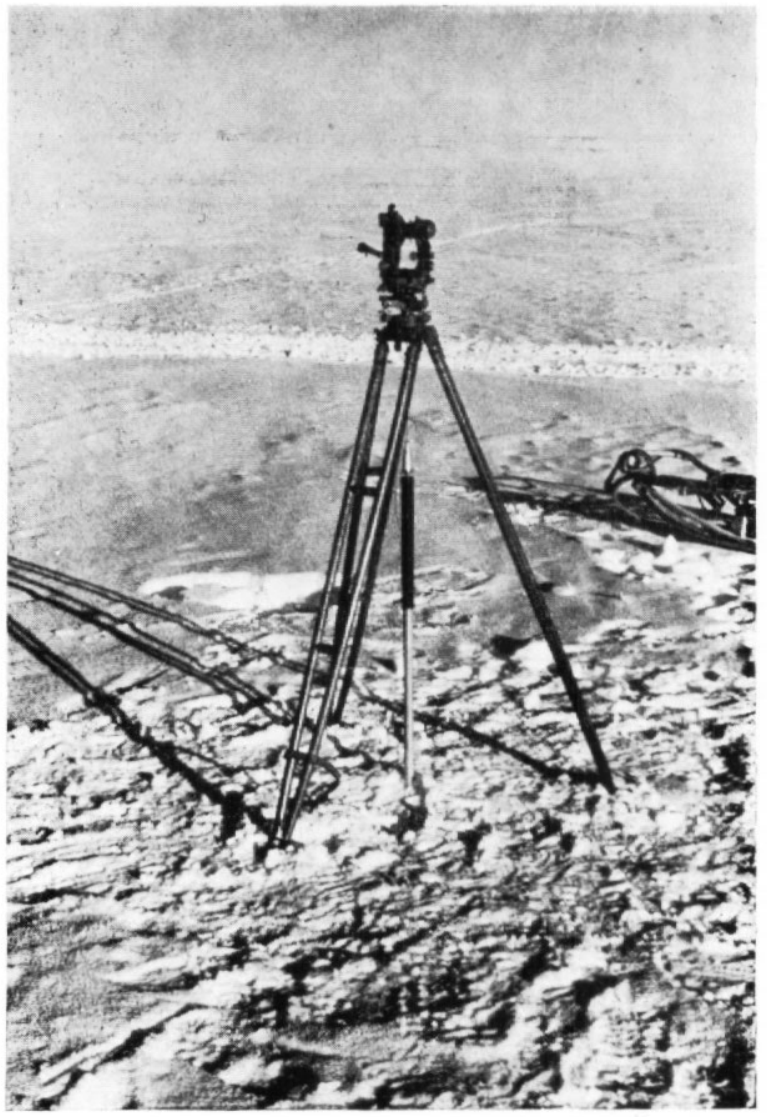

Fig. 4. The final stage in the erection of the theodolite over a stake. 
Figs. 5 and 6 show the networks of the 1960-61 and 1961-62 surveys. The trilateration and triangulation of the first survey were completed during the periods 23-26 December 1960 and 28 December 1960-4 January 1961, respectively. The trilateration of the 1961-62 survey was undertaken between 28 December 1961 and 10 January 1962 and the triangulation between 16 and 20 January 1962.

Nine survey stations were occupied in the 1960-61 survey and eight in the 1961-62 one. In each case these stations included the "declination fixed mark" from which a series of sun fixes were observed by the geophysicists of the British Antarctic Survey station. These sun fixes determined the true bearing of the line from the "declination fixed mark" to the magnetic declinometer and thus the geographical orientation of this line was known at any one time. The incorporation of this line of known azimuth into the stake triangulation network enabled the orientation of the stake pattern to be determined.

\section{Computation}

In the absence of fixed points on which to base the surveys, it is necessary to assume for the purpose of computation that stake $\mathrm{C} 3$ is fixed and that the direction of $\mathrm{C} 3-\mathrm{C} 4$ remains at $088^{\circ} 14^{\prime} 26^{\prime \prime}$ true throughout. The orientation of C3-C4 is in fact only true for 9 January 1962.

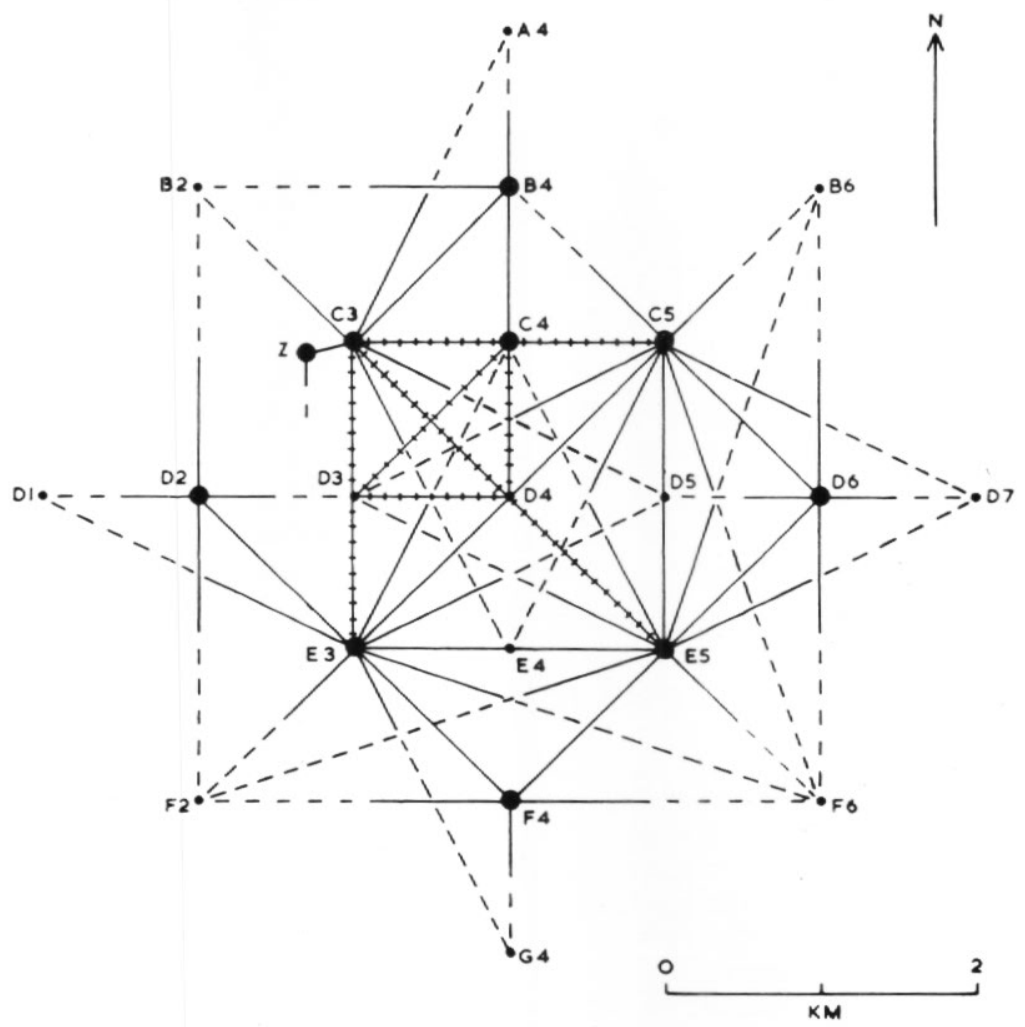

Fig. 5. Diagram of the relative movement stake pattern showing the rays observed and the distances trilaterated during the 1960-61 survey.

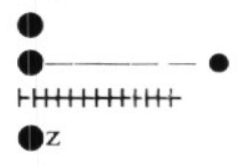

Survey station.

Ray observed from one end only.

Distance trilaterated.

"Declination fixed mark". 


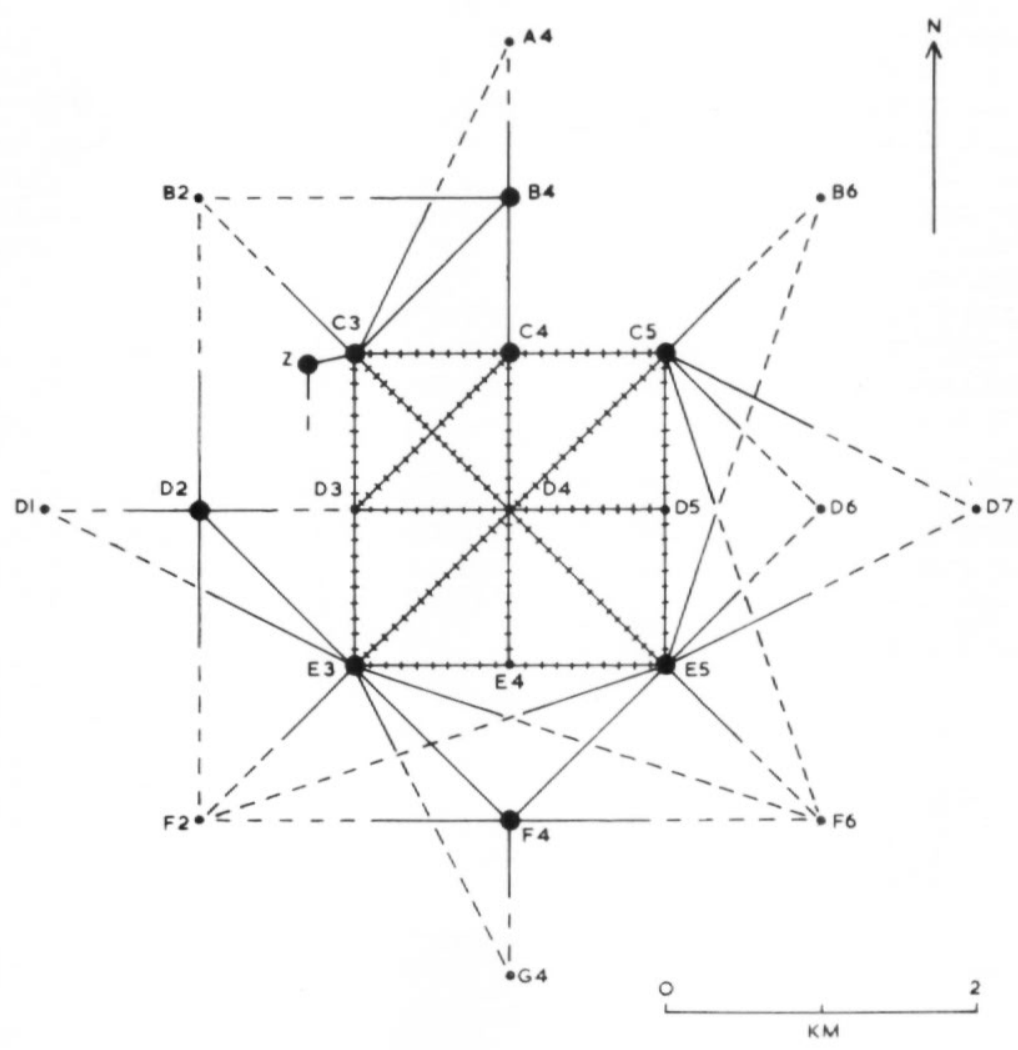

Fig. 6. Diagram of the relative movement stake pattern showing the rays observed and the distances trilaterated during the 1961-62 survey.

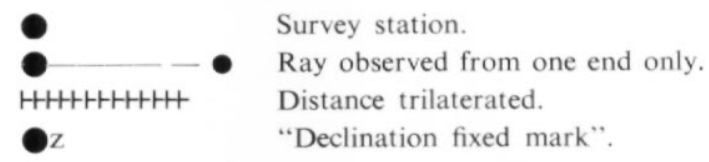

Coordinates in metres, orientated about true north, were allocated for stake C3: Northing $5000 \cdot 00$, Easting $5000 \cdot 00$.

The continuing movement of the stakes, due to the continuous surface deformation, while each survey was in progress presented the greatest problem in the computation. At any moment in time a triangle formed by three stakes possesses angles which add up to $180^{\circ}$ but because of the surface deformation the triangle changes shape. Therefore, the sum of the observed angles of a triangle during the period of a survey need not necessarily add up to $180^{\circ}$, even if the actual measurements themselves are correct. Hence there is no safeguard of conventional triangulation against the principal sources of error.

Because the change in azimuth of the magnetic declinometer- "declination fixed mark" line shows that the small annual anti-clockwise twist is virtually constant, and also because the ice shelf rests on a frictionless medium, it is reasonable to assume that the amount and direction of the relative movement of stakes is also constant throughout the period covered by the surveys (Swithinbank, 1958, p. 86). Therefore, any distances or angles measured will change at a steady rate (Swithinbank, 1958, p. 94). The two surveys provide a measure of a large number of angles and distances; it is therefore possible to compute the rate of change of these per day and then to reduce the measured values to any chosen date or epoch. After 
this adjustment it is possible to correct the triangles, whose angles should now add up to exactly $180^{\circ}$.

This system was used and epoch dates of 9 January 1961 and 9 January 1962 were adopted. This enabled the additional trilateration data of 1962 to be used, because these extra measurements were all made on 8, 9 or 10 January 1962.

The distances measured by taping were first corrected by using the temperature and National Physical Laboratory calibration corrections. These figures were then converted to metres and reduced to the epoch dates. Table I lists both these reduced figures and the calculated strain-rates. The angular measurements were then reduced to the epoch dates. The strain-rates shown by the increase in length of the distances taped indicate a direction of maximum strain from approximately east-north-east to west-south-west with a minimum strain-rate direction at right angles to this.

Table I. Trilateration Measurements and Strain-Rates

\begin{tabular}{|c|c|c|c|c|}
\hline Line & $\begin{array}{c}\text { Length }\left(l_{1}\right) \\
9 \text { January } 1961 \\
(\mathrm{~m} .)\end{array}$ & $\begin{array}{c}\text { Length }\left(l_{2}\right) \\
9 \text { January } 1962 \\
(\mathrm{~m} .)\end{array}$ & $\begin{array}{c}\text { Change }(d l) \\
(\mathrm{m} .)\end{array}$ & $\begin{array}{l}\text { Strain-rate } \\
\epsilon=\frac{d l}{l_{1}} \mathrm{yr}^{-1}\end{array}$ \\
\hline $\mathrm{C} 3-\mathrm{C} 4$ & $920 \cdot 698$ & $921 \cdot 365$ & 0.667 & $7 \cdot 25 \times 10^{-4}$ \\
\hline $\mathrm{C} 3-\mathrm{C} 5$ & $1934 \cdot 480$ & $1935 \cdot 678$ & $1 \cdot 198$ & $6.19 \times 10^{-4}$ \\
\hline C 3-D3 & $1086 \cdot 560$ & $1087 \cdot 151$ & 0.591 & $5 \cdot 44 \times 10^{-4}$ \\
\hline C 3-D4 & $1423 \cdot 741$ & $1424 \cdot 355$ & 0.614 & $4 \cdot 31 \times 10^{-4}$ \\
\hline C 3-E 3 & $2282 \cdot 252$ & $2283 \cdot 326$ & $1 \cdot 074$ & $4 \cdot 71 \times 10^{-4}$ \\
\hline C 3-E 5 & $2991 \cdot 081$ & $2292 \cdot 530$ & $1 \cdot 449$ & $4.84 \times 10^{-4}$ \\
\hline $\mathrm{C} 4-\mathrm{C} 5$ & $1013 \cdot 782$ & $1014 \cdot 313$ & 0.531 & $5 \cdot 24 \times 10^{-4}$ \\
\hline $\mathrm{C} 4-\mathrm{D} 3$ & $1424 \cdot 320$ & $1425 \cdot 092$ & $0 \cdot 772$ & $5.42 \times 10^{-4}$ \\
\hline C4-D4 & $1086 \cdot 558$ & $1086 \cdot 850$ & $0 \cdot 292$ & $2 \cdot 69 \times 10^{-4}$ \\
\hline C 5-D4 & & $1487 \cdot 473$ & & \\
\hline C 5-D5 & & $1087 \cdot 472$ & & \\
\hline C 5-E 5 & & $2282 \cdot 852$ & & \\
\hline D3-D4 & $920 \cdot 222$ & $920 \cdot 807$ & 0.585 & $6.36 \times 10^{-4}$ \\
\hline D3-E 3 & $1195 \cdot 692$ & $1196 \cdot 175$ & 0.483 & $4.04 \times 10^{-4}$ \\
\hline D4-D5 & & $1014 \cdot 713$ & & \\
\hline D4-E 3 & & $1509 \cdot 568$ & & \\
\hline D4-E 4 & & $1195 \cdot 895$ & & \\
\hline D4-E 5 & $1567 \cdot 340$ & $1568 \cdot 175$ & 0.835 & $5 \cdot 33 \times 10^{-4}$ \\
\hline D5-E 5 & & $1195 \cdot 380$ & & \\
\hline E 3-E 4 & & $920 \cdot 097$ & & \\
\hline E 3-E 5 & & $1935 \cdot 331$ & & \\
\hline E4-E 5 & & $1015 \cdot 234$ & & \\
\hline C3-DFM* & & $206 \cdot 267$ & & \\
\hline
\end{tabular}

* DFM is the "declination fixed mark". 
To determine the position of a stake, the most suitable trilateration and/or triangulation data were used to establish provisional coordinates and then the remainder of the rays were used for graphical intersection (Clark, 1923, p. 283). The final coordinates allocated to a specific stake were for the point for which the perpendicular distance from each ray involved was directly proportional to the length of that ray. This is because the linear displacement at the end of a given line, for a given error in bearing, is proportional to the length of the line, assuming that the probable error of the bearing of all the lines is the same.

Because of the continuous relative movement and also because many of the triangles were not fully observed, it is not possible to express the accuracy of the surveys in terms of the mean triangular error. However, the mean triangular error determined from the fully observed triangles is $4 \mathrm{sec}$. of arc.

\section{Relative movement}

The computed coordinates are shown in Table II, while Table III lists the relative movement of each point during the 365 days between the epoch dates of the two surveys in terms of

Table II. Coordinates of Stakes of the Relative Movement Survey

\begin{tabular}{|c|c|c|c|c|}
\hline \multirow{2}{*}{ Stake } & \multicolumn{2}{|c|}{9 January 1961} & \multicolumn{2}{|c|}{9 January 1962} \\
\hline & $\begin{array}{l}\text { Northing } \\
(\mathrm{m} .)\end{array}$ & $\begin{array}{c}\text { Easting } \\
(\mathrm{m} .)\end{array}$ & $\begin{array}{l}\text { Northing } \\
\text { (m.) }\end{array}$ & $\begin{array}{c}\text { Easting } \\
\text { (m.) }\end{array}$ \\
\hline A 4 & $7111 \cdot 61$ & $5943 \cdot 99$ & $7112 \cdot 82$ & $5944 \cdot 38$ \\
\hline B2 & $5959 \cdot 94$ & $4036 \cdot 31$ & $5960 \cdot 73$ & $4035 \cdot 74$ \\
\hline B4 & $5800 \cdot 74$ & $5892 \cdot 48$ & $5801 \cdot 22$ & $5893 \cdot 12$ \\
\hline B6 & $6148 \cdot 38$ & $7888 \cdot 54$ & $6149 \cdot 47$ & $7850 \cdot 56$ \\
\hline $\mathrm{C} 3$ & $5000 \cdot 00$ & $5000 \cdot 00$ & $5000 \cdot 00$ & $5000 \cdot 00$ \\
\hline $\mathrm{C} 4$ & $5028 \cdot 27$ & $5920 \cdot 26$ & $5028 \cdot 29$ & $5920 \cdot 93$ \\
\hline C5 & $5059 \cdot 64$ & $6933 \cdot 56$ & $5059 \cdot 80$ & $6934 \cdot 75$ \\
\hline D1 & $3843 \cdot 54$ & $2749 \cdot 69$ & $3842 \cdot 66$ & $2747 \cdot 83$ \\
\hline D2 & $3875 \cdot 93$ & $3802 \cdot 62$ & $3875 \cdot 00$ & $3801 \cdot 63$ \\
\hline D3 & $3913 \cdot 95$ & $5033 \cdot 21$ & $3913 \cdot 36$ & $5033 \cdot 21$ \\
\hline D4 & $3942 \cdot 20$ & $5952 \cdot 94$ & $3941 \cdot 91$ & $5953 \cdot 55$ \\
\hline D5 & $3973 \cdot 25$ & $6966 \cdot 63$ & $3972 \cdot 87$ & $6967 \cdot 79$ \\
\hline D6 & $4005 \cdot 30$ & $8021 \cdot 11$ & $4004 \cdot 97$ & $8023 \cdot 19$ \\
\hline D7 & $4120 \cdot 01$ & $9364 \cdot 99$ & $4119 \cdot 91$ & $9368 \cdot 19$ \\
\hline E3 & $2718 \cdot 83$ & $5070 \cdot 21$ & $2717 \cdot 76$ & $5070 \cdot 24$ \\
\hline $\mathrm{E} 4$ & $2747 \cdot 49$ & $5989 \cdot 29$ & $2746 \cdot 58$ & $5589 \cdot 88$ \\
\hline E5 & $2778 \cdot 93$ & $7003 \cdot 35$ & $2778 \cdot 13$ & $7004 \cdot 58$ \\
\hline $\mathrm{F} 2$ & $1837 \cdot 33$ & $3738 \cdot 22$ & $1835 \cdot 50$ & $3737 \cdot 73$ \\
\hline $\mathrm{F} 4$ & $1631 \cdot 60$ & $6023 \cdot 26$ & $1629 \cdot 98$ & $6024 \cdot 04$ \\
\hline F6 & $1644 \cdot 97$ & $8027 \cdot 36$ & $1643 \cdot 55$ & $8029 \cdot 43$ \\
\hline G4 & $495 \cdot 01$ & $6058 \cdot 26$ & $492 \cdot 91$ & $6059 \cdot 15$ \\
\hline
\end{tabular}


Table III. The Relative Movement of Stakes (Origin at Stake C3)

\begin{tabular}{|c|c|c|}
\hline \multirow{2}{*}{ Stake } & \multicolumn{2}{|c|}{$\begin{array}{l}\text { Relative Movement between } \\
\text { 9 January } 1961 \text { and } 9 \text { January } 1962\end{array}$} \\
\hline & $\begin{array}{l}\text { Northing } \\
(\mathrm{m} .)\end{array}$ & $\begin{array}{l}\text { Easting } \\
(\mathrm{m} .)\end{array}$ \\
\hline A4 & $1 \cdot 21$ & $0 \cdot 39$ \\
\hline B2 & 0.79 & -0.57 \\
\hline B4 & $0 \cdot 48$ & $0 \cdot 64$ \\
\hline B6 & $1 \cdot 09$ & $2 \cdot 02$ \\
\hline C3 & $0 \cdot 00$ & $0 \cdot 00$ \\
\hline C4 & $0 \cdot 02$ & $0 \cdot 67$ \\
\hline $\mathrm{C} 5$ & $0 \cdot 16$ & $1 \cdot 19$ \\
\hline D1 & $-0 \cdot 88$ & $-1 \cdot 86$ \\
\hline D2 & -0.93 & -0.99 \\
\hline D3 & -0.59 & $0 \cdot 00$ \\
\hline D4 & $-0 \cdot 29$ & $0 \cdot 61$ \\
\hline D5 & $-0 \cdot 38$ & $1 \cdot 16$ \\
\hline D6 & -0.33 & $2 \cdot 08$ \\
\hline D7 & $-0 \cdot 10$ & $3 \cdot 20$ \\
\hline E3 & $-1 \cdot 07$ & 0.03 \\
\hline E4 & -0.91 & $0 \cdot 59$ \\
\hline E5 & $-0 \cdot 80$ & $1 \cdot 23$ \\
\hline $\mathrm{F} 2$ & $-1 \cdot 83$ & -0.49 \\
\hline $\mathrm{F} 4$ & $-1 \cdot 62$ & $0 \cdot 78$ \\
\hline F6 & $-1 \cdot 42$ & $2 \cdot 07$ \\
\hline G4 & $-2 \cdot 10$ & $0 \cdot 89$ \\
\hline
\end{tabular}

northings and eastings. When considering these figures, it should be remembered that for the purpose of this surface deformation study stake $\mathrm{C} 3$ has been regarded as stationary and the line C3-C4 assumed to be of constant azimuth. Fig. 7 represents the values listed in Table III in the form of a combined map and vector movement diagram.

In order to show the surface deformation based on two other origins, the same data have been computed assuming in respective cases that stakes D7 and F6 are stationary. In both cases the line $\mathrm{C} 3-\mathrm{C} 4$ has been considered to be of fixed orientation between the two epoch dates. The relative movement of each point, again in terms of northings and eastings, is listed in Tables IV and V, the former with the assumed origin at stake D7, the latter at stake F6. 


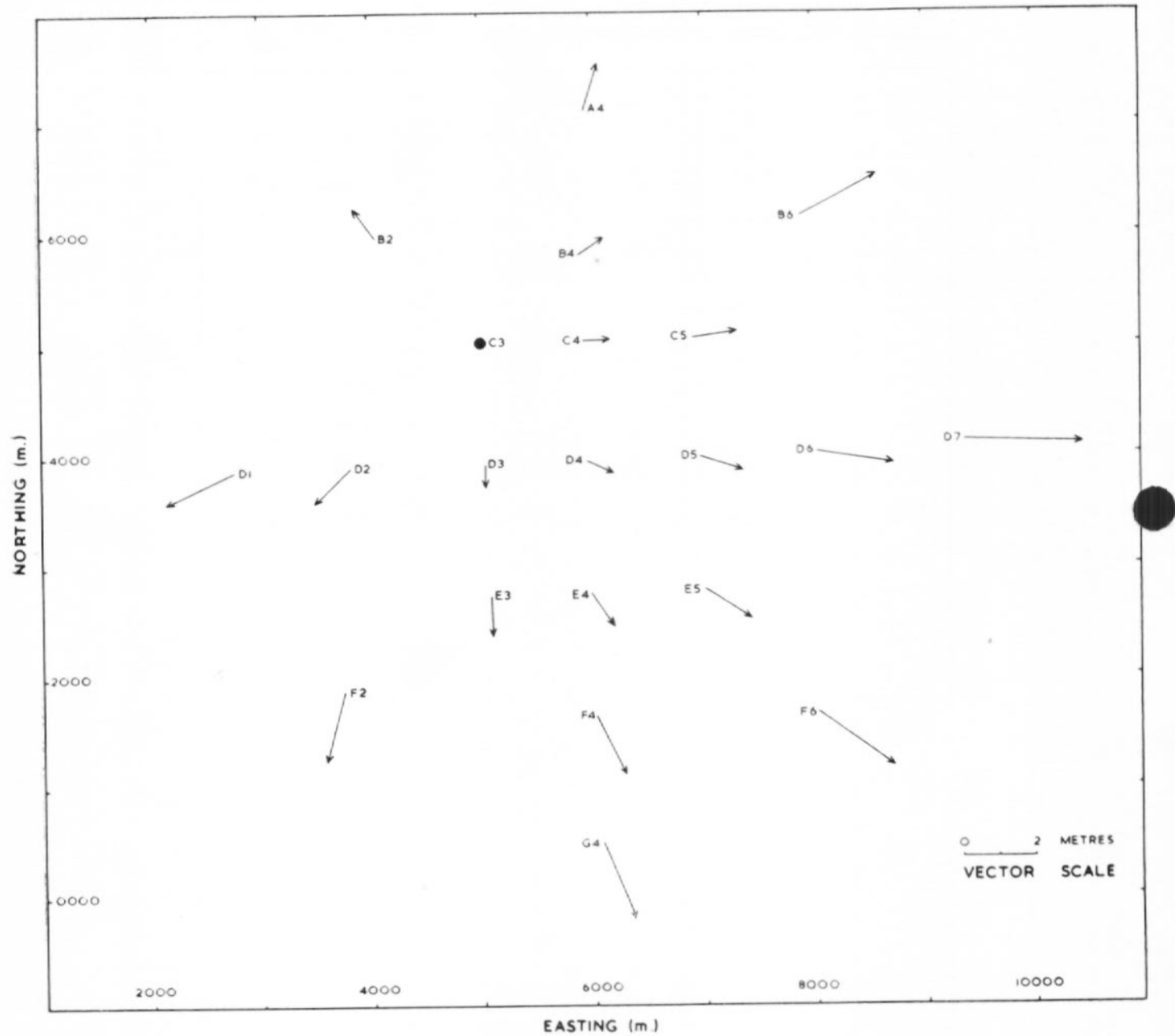

Fig. 7. Map of the relative movement stake pattern showing the stake positions and their vector movement. Origin at stake C3.

These values are also shown as combined map and vector diagrams in Figs. 8 and 9.

It can be seen from Figs. 7, 8 and 9 that the horizontal deformation taking place is mor or less that which might be anticipated in the case of an unconfined ice shelf. The relative movement in response to the accumulation of snow is largely radial, with vector length approximately proportional to the distance from the assumed origin. However, more detailed examination of these diagrams reveals a slight modification of true radial deformation. The movement vector arrows do in fact tend to turn slightly from a radial path towards the main strain-rate direction of east-north-east to west-south-west.

After computation of the increases in areas for various figures enclosed by the stakes (Table VI) it is apparent that there is greater surface deformation, i.e. spreading in a horizontal plane, near the ice front. This is well shown by the percentage increases in area of figures B2-B6-F2, B2-B6-F6 and B2-D1-F2. The relatively low rate of spreading of figure A4-B2-B6, especially considering its close proximity to the ice front, may be due to the presence of a gentle rise or undulation with an amplitude of 2 to $3 \mathrm{~m}$. and a wave-length of approximately $2 \mathrm{~km}$. This trends east-north-east to west-south-west parallel to the ice front between stakes $\mathrm{A} 4$ and B6 and occupies much of this figure (Robin, 1958, p. 120). Another undulation, again 
Table IV. The Relative Movement of Stakes (Origin at Stake D7)

\begin{tabular}{|c|c|c|}
\hline \multirow{2}{*}{ Stake } & \multicolumn{2}{|c|}{$\begin{array}{l}\text { Relative Movement between } \\
9 \text { January } 1961 \text { and } 9 \text { January } 1962\end{array}$} \\
\hline & $\begin{array}{l}\text { Northing } \\
(\mathrm{m} .)\end{array}$ & $\begin{array}{l}\text { Easting } \\
(\mathrm{m} .)\end{array}$ \\
\hline A4 & $1 \cdot 31$ & $-2 \cdot 81$ \\
\hline B2 & $0 \cdot 89$ & $-3 \cdot 77$ \\
\hline B4 & $0 \cdot 58$ & $-2 \cdot 56$ \\
\hline B6 & $1 \cdot 19$ & $-1 \cdot 18$ \\
\hline $\mathrm{C} 3$ & $0 \cdot 10$ & $-3 \cdot 20$ \\
\hline $\mathrm{C} 4$ & $0 \cdot 12$ & $-2 \cdot 53$ \\
\hline C5 & $0 \cdot 26$ & $-2 \cdot 01$ \\
\hline D1 & -0.78 & $-5 \cdot 06$ \\
\hline D2 & -0.83 & $-4 \cdot 19$ \\
\hline D3 & -0.49 & $-3 \cdot 20$ \\
\hline D4 & $-0 \cdot 19$ & $-2 \cdot 59$ \\
\hline D5 & $-0 \cdot 28$ & $-2 \cdot 04$ \\
\hline D6 & $-0 \cdot 23$ & $-1 \cdot 12$ \\
\hline D7 & $0 \cdot 00$ & 0.00 \\
\hline E3 & -0.97 & $-3 \cdot 17$ \\
\hline E4 & $-0 \cdot 81$ & $-2 \cdot 61$ \\
\hline E5 & $-0 \cdot 70$ & -1.97 \\
\hline $\mathrm{F} 2$ & $-1 \cdot 73$ & $-3 \cdot 69$ \\
\hline $\mathrm{F} 4$ & $-1 \cdot 52$ & $-2 \cdot 42$ \\
\hline F6 & $-1 \cdot 32$ & $-1 \cdot 13$ \\
\hline G4 & $-2 \cdot 00$ & $-2 \cdot 31$ \\
\hline
\end{tabular}


Table V. The Relative Movement of Stakes (Origin at Stake F6)

\begin{tabular}{|c|c|c|}
\hline \multirow{2}{*}{ Stake } & \multicolumn{2}{|c|}{$\begin{array}{c}\text { Relative Movement between } \\
9 \text { January } 1961 \text { and } 9 \text { January } 1962\end{array}$} \\
\hline & $\begin{array}{l}\text { Northing } \\
(\mathrm{m} .)\end{array}$ & $\begin{array}{l}\text { Easting } \\
(\mathrm{m} .)\end{array}$ \\
\hline A4 & $2 \cdot 63$ & $-1 \cdot 68$ \\
\hline B2 & $2 \cdot 21$ & $-2 \cdot 64$ \\
\hline B4 & $1 \cdot 90$ & $-1 \cdot 43$ \\
\hline B6 & $2 \cdot 51$ & -0.05 \\
\hline C3 & $1 \cdot 42$ & -2.07 \\
\hline $\mathrm{C} 4$ & $1 \cdot 44$ & $-1 \cdot 40$ \\
\hline $\mathrm{C} 5$ & $1 \cdot 58$ & -0.88 \\
\hline D1 & 0.54 & -3.93 \\
\hline $\mathrm{D} 2$ & 0.49 & $-3 \cdot 06$ \\
\hline D3 & 0.83 & -2.07 \\
\hline D4 & $1 \cdot 13$ & $-1 \cdot 46$ \\
\hline D5 & $1 \cdot 04$ & -0.91 \\
\hline D6 & $1 \cdot 09$ & 0.01 \\
\hline D7 & $1 \cdot 32$ & $1 \cdot 13$ \\
\hline E3 & 0.35 & $-2 \cdot 04$ \\
\hline $\mathrm{E} 4$ & 0.51 & $-1 \cdot 48$ \\
\hline E5 & 0.62 & -0.84 \\
\hline $\mathrm{F} 2$ & -0.41 & $-2 \cdot 56$ \\
\hline $\mathrm{F} 4$ & $-0 \cdot 20$ & $-1 \cdot 29$ \\
\hline F6 & 0.00 & 0.00 \\
\hline G4 & -0.68 & $-1 \cdot 18$ \\
\hline
\end{tabular}




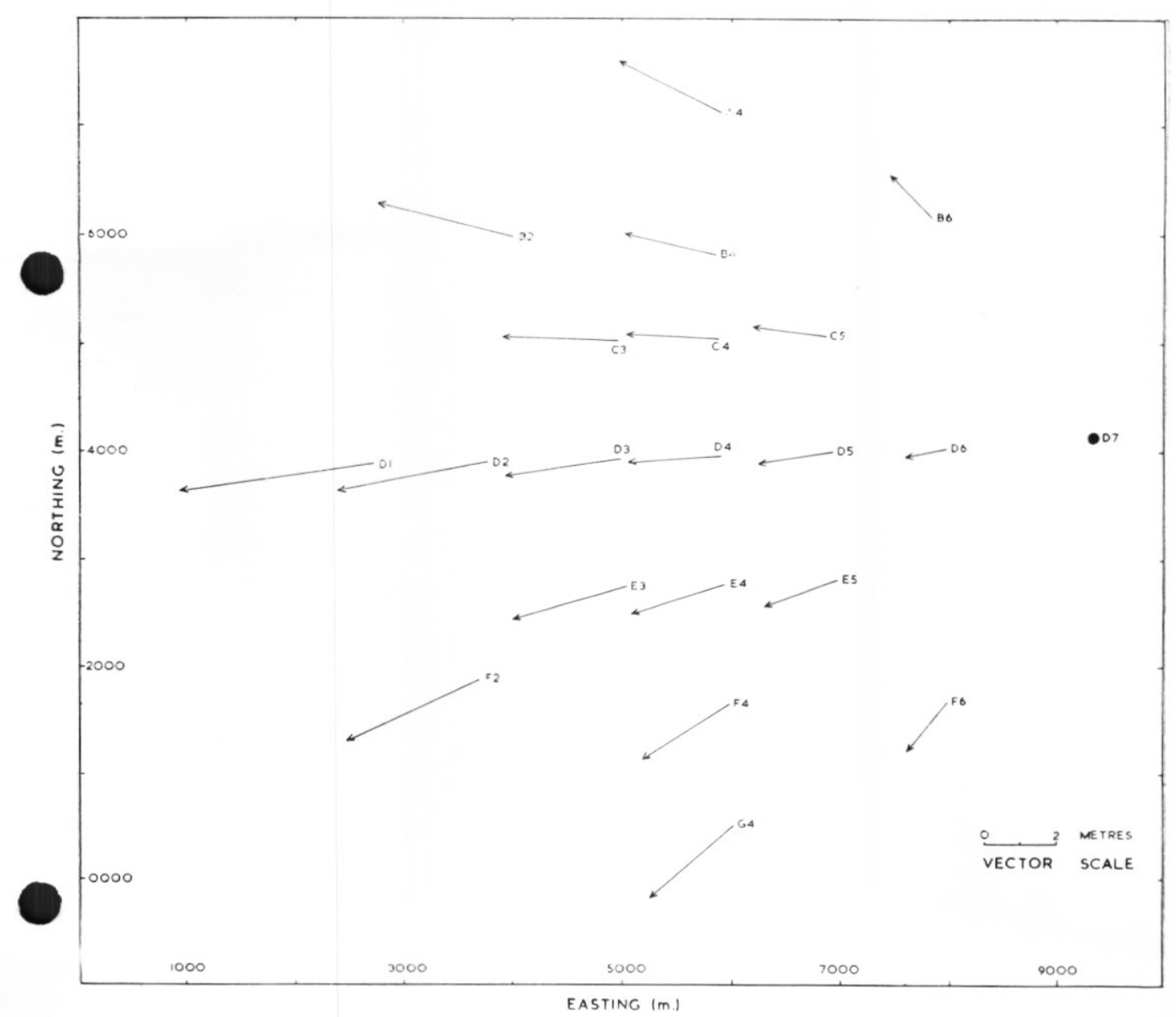

Fig. 8. Map of the relative movement stake pattern showing the stake positions and their vector movement. Origin at stake D7. 


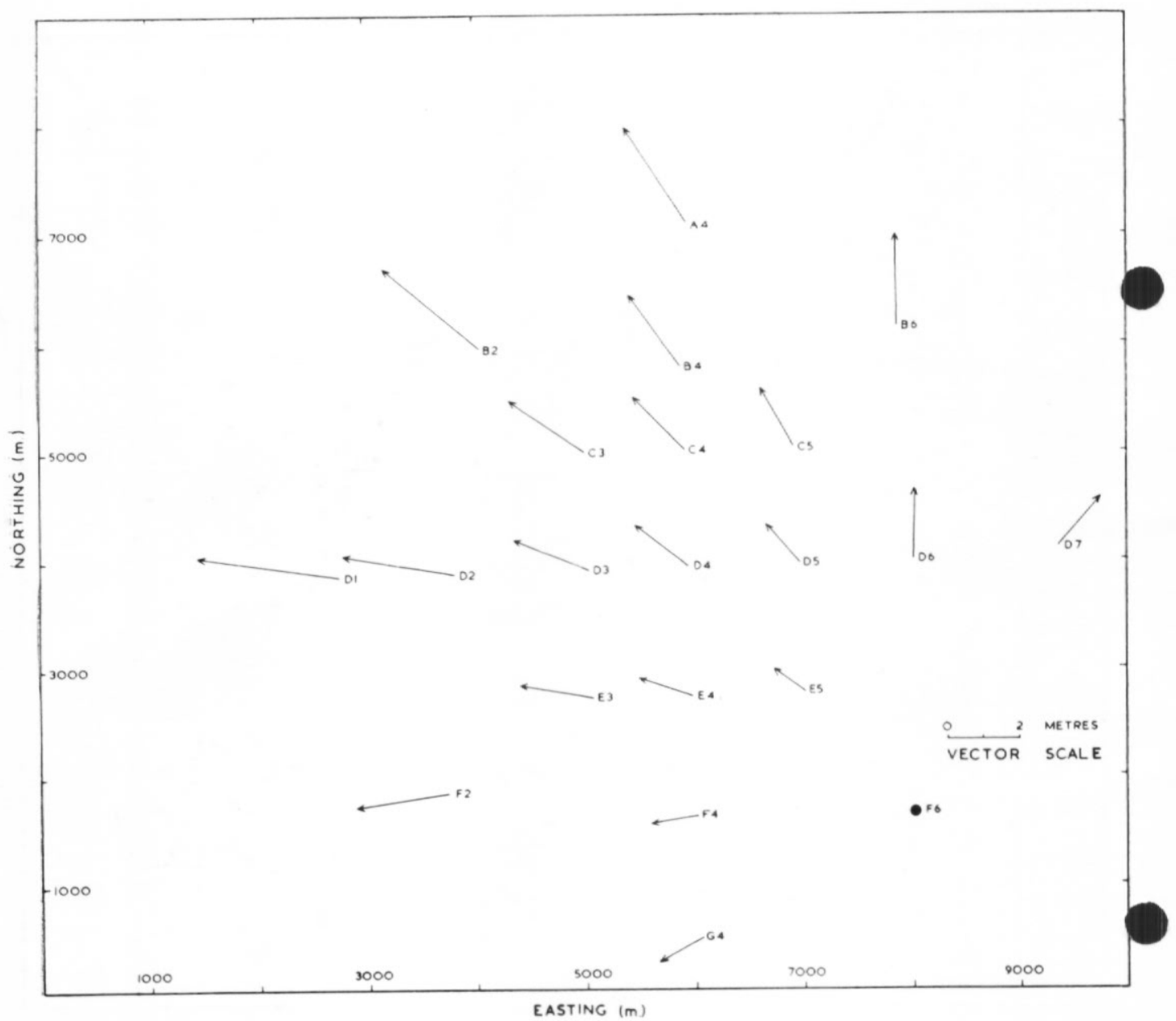

Fig. 9. Map of the relative movement stake pattern showing the stake positions and their vector movement. Origin at stake F6. 
Table Vi. Increase in Area of Various Figures Enclosed by Stakes, 9 JANUARY 1961 TO 9 JANUARY 1962

\begin{tabular}{|c|c|c|c|c|}
\hline Figure & $9 \underset{\substack{\text { Area } \\
\left(\mathrm{m}^{2}{ }^{2}\right)}}{ }$ & $9 \underset{\substack{\text { Area } \\
\left(\mathrm{m}^{2}{ }^{2}\right)}}{ }$ & $\begin{array}{c}\text { Increase } \\
\left(\mathrm{m}^{2}\right)\end{array}$ & $\begin{array}{l}\text { Increase } \\
\text { (per cent) }\end{array}$ \\
\hline C3-C5-E3-E5 & $4,414,080$ & $4,418,940$ & 4,860 & $0 \cdot 110$ \\
\hline C3-E3-E5 & $2,207,040$ & $2,209,510$ & 2,470 & $0 \cdot 111$ \\
\hline C3-C5-E5 & $2,207,030$ & $2,209,430$ & 2,400 & $0 \cdot 108$ \\
\hline C3-C5-E3 & $2,207,490$ & $2,209,890$ & 2,400 & $0 \cdot 109$ \\
\hline C5-E3-E5 & $2,206,590$ & $2,209,040$ & 2,450 & $0 \cdot 111$ \\
\hline $\mathrm{B} 2-\mathrm{B} 6-\mathrm{F} 2-\mathrm{F} 6$ & $17,548,650$ & $17,579,070$ & 30,420 & $0 \cdot 173$ \\
\hline B2-B6-F2 & $7,904,250$ & $7,923,290$ & 19,040 & $0 \cdot 240$ \\
\hline B6-F2-F6 & $9,644,400$ & $9,655,780$ & 11,380 & $0 \cdot 117$ \\
\hline B2-B6-F6 & $8,679,610$ & $8,698,000$ & 18,390 & $0 \cdot 211$ \\
\hline B2-F2-F6 & $8,869,040$ & $8,881,070$ & 12,030 & $0 \cdot 135$ \\
\hline A4-B2-B6 & $2,038,500$ & $2,040,420$ & 1,920 & 0.094 \\
\hline B6-D7-F6 & $3,183,770$ & $3,188,130$ & 4,360 & $0 \cdot 136$ \\
\hline F2-F6-G4 & $2,655,560$ & $2,658,200$ & 2,640 & 0.099 \\
\hline B2-D1-F2 & $2,336,670$ & $2,340,860$ & 4,190 & $0 \cdot 179$ \\
\hline $\begin{array}{l}\text { A4-B6-D7-F6-G4- } \\
\text { F2-D1-B2 }\end{array}$ & $27,763,200$ & $27,806,700$ & 43,500 & $0 \cdot 156$ \\
\hline
\end{tabular}

parallel to the ice front and of similar dimensions, passing between stakes E5 and F6 and through figure F2-F6-G4, may be responsible for the low value of spreading in this figure.

It is interesting to note that the rate of spreading of the Brunt Ice Shelf in this area is roughly half that of the Maudheim Ice Shelf in Dronning Maud Land (Swithinbank, 1958, p. 91). This is probably due to the fact that the area of the Maudheim Ice Shelf which was studied is partly confined by arms of the inland ice. It is therefore subjected to concentrated flow with Rapid divergence once restriction ceases, while the Brunt Ice Shelf is largely unconfined, specially in the area studied here.

Surface deformation and net accumulation shown by the stake pattern at the McDonald Ice Rumples

Fig. 10 illustrates the deformation and net accumulation of snow at a stake pattern across a syncline in the ice shelf at the McDonald Ice Rumples. The trilateration data and the computed strain-rates for this pattern are listed in Table VII. Negative strain-rate values obtained across the depression indicate a condition of compression, while the positive values indicating tension trend parallel to the anticlines. The large accumulation value obtained at stake B is due to the fact that this stake is not situated on the crest of an anticline like stakes A, C and D, but slightly down in the depression. Stakes A, C and D show small net ablation values over the period between the measurements.

The figure enclosed by stakes A, B, C and D showed a reduction in area of 4,100 m.2 (from $62,940 \mathrm{~m}^{2}$ to $58,840 \mathrm{~m} .^{2}$ ) between 14 April 1961 and 27 November 1961. This is a reduction of 6.5 per cent; the annual decrease in area of this figure is therefore 10.45 per cent. This 


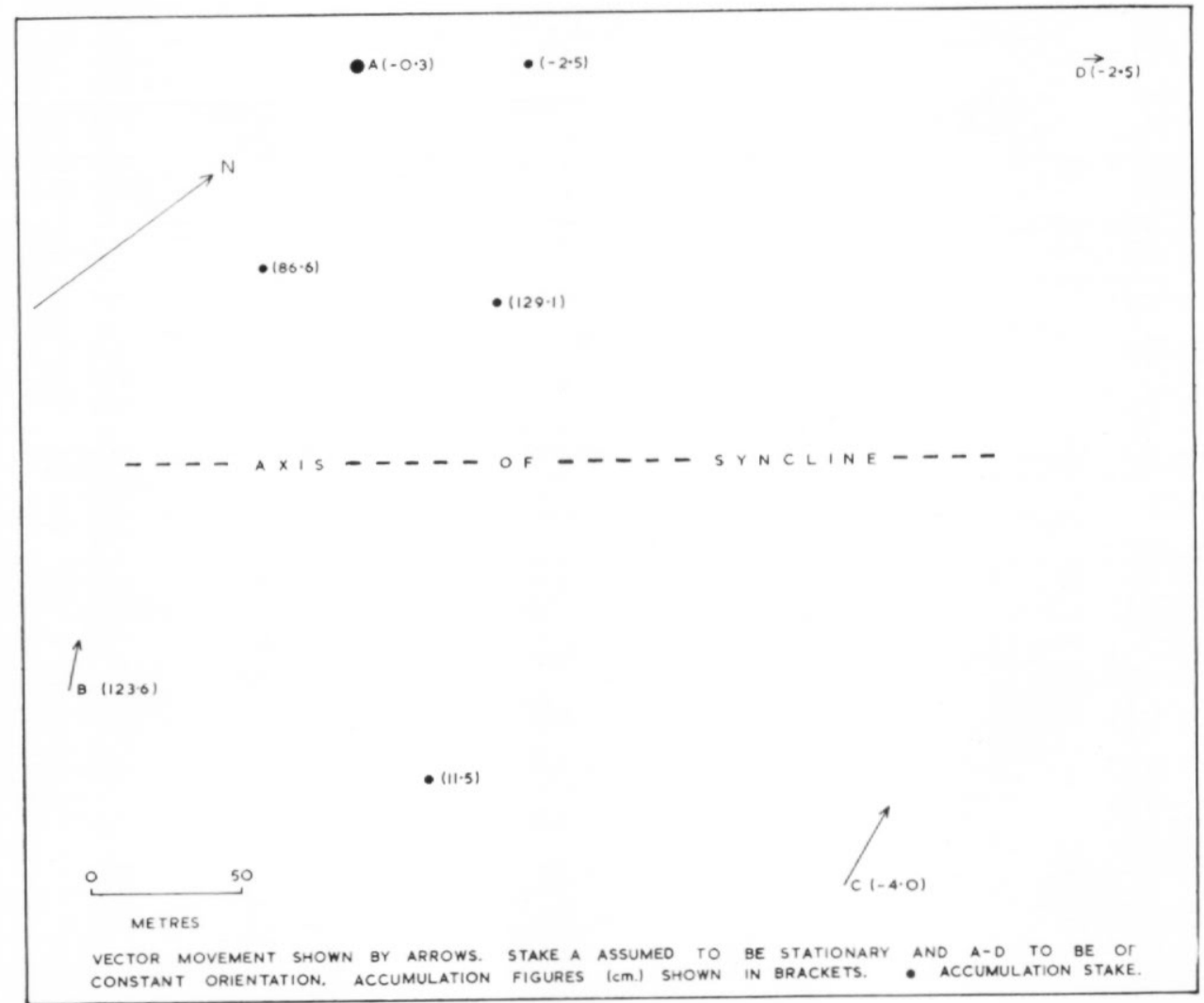

Fig. 10. The stake positions, vector movement and accumulation values determined for the McDonald Ice Rumples stake pattern.

Table VII. Trilateration Data and Strain-rates for the Stake Pattern AT THE MCDONald ICE Rumples

\begin{tabular}{|c|c|c|c|c|}
\hline Line & $\begin{array}{c}\text { Length }\left(l_{1}\right) \\
14 \text { April 1961 } \\
\text { (m.) }\end{array}$ & $\begin{array}{c}\text { Length }\left(I_{2}\right) \\
27 \text { November } 1961 \\
(\mathrm{~m} .)\end{array}$ & $\begin{array}{c}\text { Change }(d l) \\
(\mathrm{m} .)\end{array}$ & $\begin{array}{l}\text { Strain-rate } \\
\epsilon=\frac{d l}{l_{1}} \mathrm{yr}^{-1}\end{array}$ \\
\hline $\mathrm{A}-\mathrm{B}$ & $230 \cdot 32$ & $210 \cdot 26$ & $-20 \cdot 06$ & $-14.0 \times 10^{-2}$ \\
\hline $\mathrm{B}-\mathrm{C}$ & $268 \cdot 20$ & $275 \cdot 65$ & $+7 \cdot 45$ & $+4.5 \times 10^{-2}$ \\
\hline $\mathrm{C}-\mathrm{D}$ & $287 \cdot 09$ & $258 \cdot 06$ & $-29 \cdot 03$ & $-16 \cdot 3 \times 10^{-2}$ \\
\hline $\mathrm{D}-\mathrm{A}$ & $242 \cdot 40$ & $248 \cdot 27$ & $+5 \cdot 87$ & $+3.9 \times 10^{-2}$ \\
\hline $\mathrm{A}-\mathrm{C}$ & $315 \cdot 98$ & $302 \cdot 00$ & $-13 \cdot 98$ & $-7 \cdot 1 \times 10^{-2}$ \\
\hline B-D & $401 \cdot 73$ & $392 \cdot 25$ & $-9 \cdot 48$ & $-3 \cdot 8 \times 10^{-2}$ \\
\hline
\end{tabular}


reduction in area is due to the compressive deformation of the ice shelf against its point of grounding. The morphology of this area has already been described by Ardus (1965, p. 18).

\section{Absolute Movement}

An estimated movement of approximately $550 \mathrm{~m} . \mathrm{yr}^{-1}$ to the west-north-west for the ice shelf at Halley Bay was calculated by Blackwell (1960, p. 982-84) from sun fixes observed in the years 1957-59. Blackwell also described attempts to measure the movement of the ice shelf over a magnetic anomaly, but owing to the wide spacing of the observations only a provisional estimate of $460 \mathrm{~m} . \mathrm{yr}^{-1}$ to the west-north-west could be given. During 1959 Limbert (1964, p. 11) fixed by plane triangulation the positions of two icebergs thought to be grounded on the sea bed. This survey was repeated after nine months and a movement of $366 \pm 40 \mathrm{~m}$. yr. ${ }^{-1}$ in a direction $266^{\circ} \pm 5^{\circ}$ east of true north was found for the ice shelf.

In March 1960 a further survey using five grounded icebergs as fixed points was attempted at Halley Bay. During the year two of the icebergs disappeared during a storm, another changed its position with comparative rapidity and a fourth became hidden behind the disturbance of the McDonald Ice Rumples. The remaining iceberg lost part of its prominent peak, the point which had been used for observations.

In view of this situation it was decided during the survey of 1960-61 to fix the positions of 14 points on 11 icebergs, including the prominent iceberg with the marked peak. Ideal refraction conditions were necessary in order to ascertain the positions of many of these points, because without refraction few of the icebergs could be seen. Unfortunately, very strong refraction makes it impossible to carry out accurate observations. In addition to this problem, there is great difficulty in being certain that the same feature is being observed from different survey stations. On returning to repeat these observations after one year it is often impossible to pick out the features observed in the previous survey, despite keeping detailed records. This is due to the change in position of each survey station relative to the icebergs during the year, to the rapid erosion of the icebergs and in some cases to the disappearance of some of the icebergs. During the 1961-62 survey only the observed point on the iceberg with the prominent peak could be fixed with certainty.

In addition to the orthodox triangulation of the grounded icebergs, the suggestion of Dr. Robin, of the Scott Polar Research Institute, to use the Decca windfinder radar set, which is normally used for tracking the flights of meteorological radio-sonde balloons, for determining the positions of the front profiles of the icebergs was attempted. The failure of the range unit of the set in 1960 made this impossible. However, in 1961 a new radar set of the same type was available and six surveys were carried out on 17 February, 7 May, 26 June, 7 August, 19 September and 13 December. All the observed echoes for each $1^{\circ}$ change in azimuth for the sector occupied by the grounded icebergs were plotted in order to detect the apparent movement of the icebergs. From this it was hoped to determine the forward and lateral movements of the radar set and hence the movement of the ice shelf itself. However, when the echoes were plotted the edges of the icebergs were so ill-defined that it was difficult to discern the movement, which in most cases should have been largely angular. The winter surveys contained echoes from pressure ridges and brash among the sea ice, due to conditions of strong refraction. Therefore, from the results of the radar observations it was impossible to measure the absolute movement of the ice shelf as was hoped, but it was possible to detect any major relative movement among the icebergs themselves. One iceberg which appeared to have been stationary throughout the year and which still furnished good points for plane triangulation was shown by the radar observations to have moved. This iceberg was therefore of no value as a "fixed point". Similarly, no movement was discernible in the case of the pointed iceberg and it is considered to have been stationary throughout the year. The positions of the front profiles of the icebergs at the time of one of the surveys are shown in Fig. 2.

The triangulation of the icebergs was carried out in conjunction with the relative movement surveys of 1960-61 and 1961-62. The observations were based on the line C3-C4 whose true orientation was known throughout because of the incorporation of the "declination fixed mark"-magnetic declinometer line into the surveys. This line showed an anti-clockwise twist of 14'34" between the epoch dates of the two surveys, 9 January 1961 and 9 January 1962. The angular observations made from stakes $\mathrm{C} 3$ and $\mathrm{C} 4$ to the pointed iceberg which furnished 
the only acceptable survey point were reduced to the epoch dates in the same manner as the angles of the relative movement survey. The bearing of the iceberg from stake C3 was $15^{\circ} 58^{\prime} 57^{\prime \prime}$ west of true north on 9 January 1961 and $14^{\circ} 46^{\prime} 25^{\prime \prime}$ west of true north on 9 January 1962.

The apparent positions of the iceberg were computed for the two epoch dates and the distance and direction of its apparent movement was calculated. This distance was in fact the true movement of stake $\mathrm{C} 3$ and the direction was the reverse of the actual movement of this stake. The absolute movement of stake C 3 was found to be $363 \pm 3 \mathrm{~m}$. yr. ${ }^{-1}$ on a true bearing of $241^{\circ} \pm 10^{\circ}$.

Because of the distance of the iceberg from the base line, computed to be $16.791 \mathrm{~km}$. and $16.875 \mathrm{~km}$. from stake C3 on 9 January 1961 and 9 January 1962, respectively, and the relatively short length of the base line (approximately $1 \mathrm{~km}$.), the angle subtended at the iceberg was only $3^{\circ} 00^{\prime} 04^{\prime \prime}$ and $3^{\circ} 00^{\prime} 33^{\prime \prime}$ on the two successive epoch dates. The major errors in determining the position of the iceberg were therefore the character of this angle and the nature of the iceberg peak as a target.

The iceberg itself was no longer of the tabular type, although of fairly large size. It had developed a distinct peak at one end after having turned partly over due to the effects of prolonged submarine erosion. Continuing submarine erosion could possibly have resulted in small changes in the position of the iceberg about its point of grounding in the period between the two surveys. These were not discernible from the ice shelf, but they could possibly have been sufficient to affect the accuracy of the survey.

In comparison with these sources of error, the errors originating from the measurement of the azimuth of the "declination fixed mark"- -magnetic declinometer line during each survey, the length and orientation of the base line $\mathrm{C} 3-\mathrm{C} 4$ and the observations from stakes $\mathrm{C} 3$ and $\mathrm{C} 4$ to the iceberg are relatively small. The triangular error of the observations cannot be determined exactly, but an error of $\pm 10 \mathrm{sec}$. of arc in the angle subtended at the iceberg is equivalent to $\pm 15 \mathrm{~m}$. in the range and therefore equal to $\pm 1 \mathrm{~m}$. and $\pm 5^{\circ}$ in the distance and direction of the apparent movement of the iceberg. Considering the nature of the target, i.e. the peak of the iceberg, this would be of an extremely high order of accuracy, and it would probably be unattainable. A more realistic assessment of the error in the angle subtended at the iceberg is probably $\pm 20 \mathrm{sec}$. which is equivalent to $\pm 1.7 \mathrm{~m}$. at that range. This would be an error of $\pm 31 \mathrm{~m}$. in range and therefore a probable error of $\pm 3 \mathrm{~m}$. and $\pm 10^{\circ}$ in the distance and direction of the apparent movement of the iceberg.

\section{Mass Balance}

Using the relationship between the net accumulation, the equilibrium thickness and the degree of spreading (assumed to be constant with depth), which have already been described, it is now possible to calculate the amount of melting or freezing taking place at the lower surface of the ice shelf in the area covered by the relative movement surveys.

The positive character of the regime of the ice shelf with its relatively regular net annual accumulation, and the uniformity and constancy of the surface elevation despite this accumulation both indicate that the Brunt Ice Shelf in the Halley Bay area is in a state of approximate equilibrium. A condition of uniform velocity of spreading at all depths cannot be justified so easily, as this certainly cannot apply at the ice front. However, in a bore hole sunk to a depth of $100 \mathrm{~m}$. in the Maudheim Ice Shelf, no evidence of velocity variations were discernible (Swithinbank, 1958, p. 92).

The water equivalent of the volume added to the surface of each figure to be considered in these calculations is the product of the water equivalent of the net accumulation for the period between the epoch dates of the two surveys, $0.355 \mathrm{~m}$. (Ardus, 1965, p. 29), and the mean area of each figure (obtained from the computed area for each epoch date).

The thickness of ice, calculated from the elevation of the ice shelf, multiplied by the increase in area gives the value for the volume of the ice spread beyond the confines of the figure as it was at the time of the first survey (9 January 1961) until the time of the second survey ( 9 January 1962). The product of this volume of ice dispersed by spreading and the mean density of the ice mass is the water equivalent of the volume dispersed. The mean density for an ice shelf $137 \mathrm{~m}$. thick was calculated from equation (6) of Schytt (1958, p. 122) to be $0 \cdot 80 \mathrm{~g} . / \mathrm{cm} .^{3}$. 
In these calculations, applied to the figures listed in Table VI, the water equivalent of the volume added to the upper surface of the ice shelf always exceeds the water equivalent of the volume dispersed by spreading. Therefore, the difference is the water equivalent of the volume melted from the lower surface. Dividing the water equivalent of the volume melted by the mean area of the figure gives the water equivalent of the thickness of ice melted from the lower surface. Multiplication of this figure by the assumed density at the lower surface $\left(0.91 \mathrm{~g} . / \mathrm{cm}^{3}\right)$ gives the actual thickness of ice removed by melting.

Table VIII lists the water equivalent of the thickness of ice melted from the lower surface of the ice shelf over the area of each figure, the actual thickness of ice melted, the percentage of the net accumulation dissipated by melting and the percentage dissipated by spreading. The percentage increase in area is also given.

TABle VIII. Bottom Melting

\begin{tabular}{|c|c|c|c|c|c|}
\hline Figure & $\begin{array}{c}\text { Thicknes } \\
\text { Ice } \\
(\mathrm{cm} .)\end{array}$ & $\begin{array}{l}\text { of Ice Melted } \\
\text { Water Equivalent } \\
(\mathrm{cm} .)\end{array}$ & $\begin{array}{l}\text { Dissipation of Net } \\
\text { By Bottom Melting } \\
\text { (per cent) }\end{array}$ & $\begin{array}{l}\text { Accumulation } \\
\text { By Deformation } \\
\text { (per cent) }\end{array}$ & $\begin{array}{c}\text { Increase in } \\
\text { Area } \\
\text { (per cent) }\end{array}$ \\
\hline $\mathrm{C} 3-\mathrm{C} 5-\mathrm{E} 3-\mathrm{E} 5$ & $25 \cdot 7$ & $23 \cdot 4$ & 66 & 34 & $0 \cdot 110$ \\
\hline C3-E3-E5 & $25 \cdot 4$ & $23 \cdot 2$ & 65 & 35 & $0 \cdot 111$ \\
\hline C3-C5-E5 & $25 \cdot 8$ & $23 \cdot 5$ & 66 & 34 & $0 \cdot 108$ \\
\hline C3-C5-E3 & $25 \cdot 8$ & $23 \cdot 5$ & 66 & 34 & $0 \cdot 109$ \\
\hline C5-E3-E5 & $25 \cdot 6$ & $23 \cdot 3$ & 66 & 34 & $0 \cdot 111$ \\
\hline $\mathrm{B} 2-\mathrm{B} 6-\mathrm{F} 2-\mathrm{F} 6$ & $18 \cdot 1$ & $16 \cdot 5$ & 46 & 54 & $0 \cdot 173$ \\
\hline $\mathrm{B} 2-\mathrm{B} 6-\mathrm{F} 2$ & $10 \cdot 0$ & $9 \cdot 1$ & 26 & 74 & $0 \cdot 240$ \\
\hline B6-F2-F6 & $24 \cdot 7$ & $22 \cdot 5$ & 63 & 37 & $0 \cdot 117$ \\
\hline B2-B6-F6 & $13 \cdot 5$ & $12 \cdot 3$ & 35 & 65 & $0 \cdot 211$ \\
\hline $\mathrm{B} 2-\mathrm{F} 2-\mathrm{F} 6$ & $22 \cdot 6$ & $20 \cdot 6$ & 58 & 42 & $0 \cdot 135$ \\
\hline $\mathrm{A} 4-\mathrm{B} 2-\mathrm{B} 6$ & $27 \cdot 5$ & $25 \cdot 1$ & 71 & 29 & 0.094 \\
\hline B6-D7-F6 & $22 \cdot 5$ & $20 \cdot 5$ & 58 & 42 & $0 \cdot 136$ \\
\hline F2-F6-G4 & $27 \cdot 0$ & $24 \cdot 6$ & 69 & 31 & $0 \cdot 099$ \\
\hline $\mathrm{B} 2-\mathrm{D} 1-\mathrm{F} 2$ & $17 \cdot 3$ & $15 \cdot 8$ & 45 & 55 & 0.179 \\
\hline $\begin{array}{l}\mathrm{A} 4-\mathrm{B} 6-\mathrm{D} 7-\mathrm{F} 6- \\
\mathrm{G} 4-\mathrm{F} 2-\mathrm{D} 1-\mathrm{B} 2\end{array}$ & $20 \cdot 1$ & $18 \cdot 3$ & 52 & 48 & $0 \cdot 156$ \\
\hline
\end{tabular}

From Table VIII it is apparent that those figures with a high rate of deformation also appear to have a relatively small amount of melting on their lower surfaces, and therefore they seem to dissipate little of their net surface accumulation by bottom melting. It is also notable that these figures (B2-B6-F2, B2-B6-F6 and B2-D1-F2) lie relatively close to the ice front.

Bottom melting probably varies greatly from one place to another, depending on the amount of heat transported by sea-water circulation and on the temperature of the ice $\left(-19^{\circ} \mathrm{C}\right.$ at a depth of $12 \mathrm{~m}$. at Halley Bay, which is the same as the mean annual air temperature). Because of the temperature of the ice, the water will lose heat during the whole of its passage beneath the ice shelf and melting from the lower surface should decrease with increasing distance from the ice front. 
Assuming that melting from the lower surface takes place rapidly near the ice front and perhaps even more rapidly beneath the bays where tidal currents may be channelled, it may be assumed that everywhere within the octagon covered by the survey (A4-B6-D7-F6-G4F2-D1-B2) loses more than $20-25 \mathrm{~cm}$. water equivalent per year in this way. Hence those areas showing excessive spreading, and therefore smaller amounts of bottom melting because of the assumed constant ice shelf thickness of $137 \mathrm{~m}$., are believed to be thinning at the same rate at which the correct bottom melting (i.e. at least $20-25 \mathrm{~cm}$. water equivalent per year) exceeds that calculated. In addition, near the ice front the lower accumulation values will produce extra thinning equivalent to the difference between the normal, i.e. $0 \cdot 355 \mathrm{~m}$., and the reduced accumulation amounts.

Excessive accumulation in the bays in the ice front (well above $5 \mathrm{~m} . \mathrm{yr}^{-1}$ in places) is balanced by more rapid bottom melting and these areas act like rift valleys, being bounded by crevasses on either side. Spreading may be above normal, but it could not accommodate this excess of accumulation. However, as little or no apparent change is discernible in the surface topography, it can be seen that a state of near-equilibrium exists in these places.

Between the ice front and the inland boundary of the ice shelf undulations tend to be parallel to the latter, except around the McDonald Ice Rumples, and they are probably perpendicular to the direction of movement of the ice shelf. The direction of the maximum strain-rate and the direction of absolute movement measured in the vicinity of Halley Bay are both virtually parallel to the inland ice boundary, i.e. west-south-west to east-north-east, and parallel to the undulations. This is presumably due to the influence of the McDonald Ice Rumples, which divert the flow of the ice shelf in the vicinity of Halley Bay to the west or west-south-west, away from the point of grounding. This movement may be assisted by the south-westerly sea current which carries any floating icebergs past Halley Bay. The crevassing of the ice front between the McDonald Ice Rumples and Emperor Bay illustrates the degree of movement which is taking place.

Assuming a constant strain-rate of $5 \times 10^{-4} \mathrm{yr}^{-1}$ over the $35 \mathrm{~km}$. of ice shelf between Halley Bay and the inland ice, only $17.5 \mathrm{~m}$. of movement to the north-north-west can be accounted for by spreading. This is equivalent to a change of $2.5^{\circ}$ in the direction of the absolute movement of stake $\mathrm{C} 3$, and therefore well within the error of the measurement made of that direction.

Because of the influence of the McDonald Ice Rumples, it is not possible to attempt assessment of the speed of flow of the inland ice at its boundary with the ice shelf using the data available at present.

\section{Conclusions}

The deformation of various figures enclosed by stakes of the relative movement pattern indicates that in areas of normal ice shelf near Halley Bay, which are in an equilibrium condition, approximately $20-25 \mathrm{~cm}$. water equivalent is melted from the lower surface each year. This is equivalent to $60-70$ per cent of the net accumulation, the remainder of which is dissipated by spreading. Greater bottom melting, a higher rate of spreading and reduced accumulation cause thinning in the vicinity of the ice front.

An absolute movement of $363 \pm 3 \mathrm{~m} . \mathrm{yr}^{-1}$ in a direction $241^{\circ} \pm 10^{\circ}$ east of true north was measured for the ice shelf at Halley Bay in 1961. This is believed to be partly due to the grounding of the ice shelf at the McDonald Ice Rumples which halt and deflect the movement of the ice.

\section{ACKNOWLEDGEMENTS}

I wish to thank fellow members of the British Antarctic Survey for help during the field work which was done from Halley Bay between January 1960 and February 1961.

The laboratory work was carried out in the Department of Geology, University of Birmingham, by kind permission of Professor F. W. Shotton. I wish to record my gratitude to Dr. R. J. Adie for much help and advice concerning many aspects of the work. 


\section{REFERENCES}

Ardus, D. A. 1965. Morphology and Regime of the Brunt Ice Shelf and the Adjacent Inland Ice, $1960-61$. British Antarctic Survey Bulletin, No. 5, 13-42.

Blackwell, M. J. 1960. Recent Scientific Activities at Halley Bay: International Geophysical Co-operation, 1959. Nature, Lond., 187, No. 4742, 982-84.

Clark, D. 1923. Plane and Geodetic Surveying. Vol. I. Plane Surveying. London, Constable and Co. Ltd.

Limbert, D. W. S. 1964. The Absolute and Relative Movement, and the Regime of the Brunt Ice Shelf near Halley Bay. British Antarctic Survey Bulletin, No. 3, 1-11.

RobIN, G. DE Q. 1958. Glaciology. III. Seismic Shooting and Related Investigations. Norwegian-British-Swedish Antarctic Expedition, 1949-52. Scientific Results, 5, 3-134.

Schyтt, V. 1958. Glaciology. II. The Inner Structure of the Ice Shelf at Maudheim as Shown by Core Drilling. Norwegian-British-Swedish Antarctic Expedition, 1949-52. Scientific Results, 4, C, 113-51.

Swithinbank, C. W. M. 1958. Glaciology. I. The Movement of the Ice Shelf at Maudheim. NorwegianBritish-Swedish Antarctic Expedition, 1949-52. Scientific Results, 3, C, 77-96. 